\title{
Design of a Wideband Inductively Coupled Loop Feed Patch Antenna for UHF RFID Tag
}

\author{
Mohd Saiful Riza BASHRI, Muhammad Ibn IBRAHIMY, S. M. A MOTAKABBER \\ Dept. of Electrical and Computer Engineering, International Islamic University Malaysia, 53100 Kuala Lumpur, Malaysia \\ mohdsaifulriza@yahoo.com, ibrahimy@iium.edu.my, amotakabber@iium.edu.my
}

\begin{abstract}
A planar wideband patch antenna for ultra-high frequency (UHF) radio frequency identification (RFID) tag for metallic applications is presented in this research work. Three different shape patches are inductively coupled to a triangle loop to form wide impedance bandwidth for universal application UHF (860-960 MHz) RFID. The structure of the proposed antenna exhibits planar profile to provide ease of fabrication for cost reduction well suited for mass production. The simulation of the antenna was carried out using Finite Element Method (FEM) based software, Ansoft HFSS v13. The simulated and measured impedance bandwidth of $113 \mathrm{MHz}$ and $117 \mathrm{MHz}$ (Return Loss $\geq 6 \mathrm{~dB}$ ) were achieved to cover the entire UHF RFID operating frequency band worldwide. The simulated and measured radiation patterns at the operating frequency of $915 \mathrm{MHz}$ are in good agreement. Moreover the simulated maximum antenna gain at the bore sight direction in free space and when mounted on $200 \times 200 \mathrm{~mm}^{2}$ metal plate are $-5.5 \mathrm{dBi}$ and $-9 \mathrm{dBi}$ respectively which is enough to provide reasonable read range over the entire UHF RFID system operating band.
\end{abstract}

\section{Keywords}

Complex impedance matching, patch antenna, radio frequency identification (RFID), metallic object, ultra high frequency (UHF)

\section{Introduction}

Recently, Radio Frequency Identification (RFID) technology is gaining traction in various sectors due to its numerous advantages such as it does not require line of sight, high read distance, fast date rate and large storage capacity as compared to conventional barcode technology [1]. Some of the sectors utilizing RFID are supply chain management, logistics, access control and real time location service (RTLS) etc. RFID in its basic form consists of tag, attached to an object to be tracked and reader whose function is to read the information contained inside the tag memory. Generally, RFID can be categorized into several types based on their operating frequencies, power source and protocols that govern its communication. Low frequency (LF) and high frequency (HF) systems are operated based on near-field communication thus having limited read range up to only 1 meter. As for ultra-high frequency (UHF) and microwave systems, the interaction between tag and reader is accomplished via propagating electromagnetic wave hence able to provide longer read range. As such, UHF based RFID technology is rapidly becoming the preferred solution.

Tag is made up of a microchip and an antenna connected together. To operate the microchip, ample power is needed. Due to cost factors, most systems employ passive tag where there is no on board power source such as battery to provide the power to the microchip. To circumvent this matter, tag antenna extracts the energy from the incident radio wave emitted by the reader to be delivered to the microchip. In addition, in the absence of transmitter on the tag, a special modulation technique is utilized in RFID called backscattering modulation [1]. In this method, the electromagnetic wave from the reader is modulated and reflected back to the reader. The modulation is performed by the tag microchip by changing its input impedance between two states which are matched and mismatched to the antenna input impedance to represent the binary code ' 1 ', and ' 0 ' of the information to be transmitted to the reader. The corresponding high (mismatched) and low (matched) power of the reflected wave received is then demodulated by the reader.

Antenna design is of great importance in passive UHF RFID system to ensure tag is able to operate properly [2], [3]. Although numerous works have been done in designing tag antenna, there are still many open issues that require further studies and research in order to truly exploit its potential. One of the issues is performance degradation of commonly used label typed dipole tag antenna [4-6] when placed on metal surface due to cancellation of tangential electric current at the boundary between the antenna and the metal surface [7], [8]. One of the many attempts to mitigate the problem is to separate the antenna and the metal surface by using a foam spacer to create constructive interference between the incoming and reflected signal. However, it results in thicker antenna structure which is unsuitable for RFID applications.

Another method that has been widely adopted is the use of microstrip patch antenna due to its grounded structure. When mounted on metal objects, the metal plane will act as an extension of its ground plane hence giving little effect to the antenna performance. Several microstrip an- 
tennas for UHF RFID tag have been proposed by [9-13]. However, they exhibit narrow bandwidth. To operate worldwide, the required impedance bandwidth should be able to cover the whole frequency range of UHF RFID band (860-960 MHz) [14]. List of operating frequency of several countries is shown in Tab. 1 . Several solutions to improve the impedance bandwidth of patch antenna for RFID were presented by [15-19]. However, the structures of the presented antennas require multi or cross-layered configuration which will add significant manufacturing cost to the antenna fabrication due to additional process required. Moreover, the impedance bandwidth performances of the antenna were evaluated based on the halfpower bandwidth (Return Loss $\geq 3 \mathrm{~dB}$ ) that accounts for only half of the power accepted by the tag antenna to be actually delivered to the tag's microchip. Several complete planar patch antenna have been proposed by [20-23] although with limited bandwidth.

\begin{tabular}{|c|c|}
\hline Region/country & $\begin{array}{c}\text { Operating frequency, } \\
f(\mathrm{MHz})\end{array}$ \\
\hline North America & $902-928$ \\
\hline Europe & $865-868$ \\
\hline China & $917-922$ \\
\hline Japan & $916-921 \& 952-956$ \\
\hline Australia & $918-926$ \\
\hline Hong Kong & $865-868 \& 920-925$ \\
\hline Taiwan & $922-928$ \\
\hline
\end{tabular}

Tab. 1. List of operating frequency for several major countries.

This letter proposes a planar wideband microstrip patch RFID tag antenna design for metallic applications. The wide impedance bandwidth is achieved by utilizing three radiating elements to excite three resonances close to each other. The complex impedance matching with the referenced microchip, Alien Higgs-3, with impedance value of $Z_{\mathrm{c}}=31-\mathrm{j} 212 \Omega$ and sensitivity, $P_{\mathrm{th}}$ of $-18 \mathrm{dBm}$ is realized by using inductively coupled triangle loop structure. The structure of the proposed antenna does not incorporate any via hole or shorting wall/plate which further simplify its fabrication process. The proposed antenna design concept and configuration will be explained in Sec. 2. Section 3 demonstrates the simulation and measurement results while conclusions are drawn in Sec. 4.

\section{Antenna Design and Configuration}

Several important factors for designing antenna for UHF RFID tag have been comprehensively presented by [2], [3]. The aim of this research is to design metal mountable tag antenna for use in metallic applications where typical label-type dipole antenna suffers performance deg- radation like shift in operating frequency that leads to impedance mismatch and distorted radiation pattern. Moreover, to realize a universal tag that is able to operate across the world, a wideband characteristic is required which is quite challenging for patch antenna due to its inherent narrow bandwidth. To begin with the antenna design, Alien Higgs-3 was selected as a referenced microchip [24]. The impedance of the microchip, $Z_{\mathrm{c}}$, is $31-\mathrm{j} 212 \Omega$ at $915 \mathrm{MHz}$. Typically, most antenna is designed to match with $50 \Omega$ characteristic impedance of feeding line such as coaxial cable. However, for tag antenna, its impedance must be conjugate matched with the impedance of the microchip which is connected to [25]. This is very crucial particularly for passive UHF RFID system where the tag itself does not possess its own power source to operate the microchip [2] and all the power needed is extracted from the electromagnetic signal emitted by the reader. To ensure sufficient power is delivered to the microchip, impedance matching is crucial. The evaluation of the matching efficiency can be evaluated based on return loss, $R L$ as expressed in (1) below [26]

$$
R L(\mathrm{~dB})=-20 \log _{10}|\Gamma|
$$

where $\Gamma$ is the reflection coefficient at the antenna input terminal. $\Gamma$ can be calculated as shown in (2) below [25]

$$
\Gamma=\frac{Z_{\mathrm{c}}-Z_{\text {in }}^{*}}{Z_{\mathrm{c}}+Z_{\text {in }}^{*}}
$$

where $Z_{\text {in }}$ is the antenna input impedance.

There are several impedance matching techniques that have been proposed such as T-matching network, inductive coupled feed loop, nested loop, open end microstrip line shorted to ground, proximity-coupled feed and open stub feed [2], [12], [23], [27]. In this work, an inductively coupled loop structure in the form of triangle was used for complex impedance matching with the referenced microchip. The resulting input impedance seen at the input terminal of the antenna due to the triangle feed loop is given by (3) [27]

$$
Z_{\text {in }}=Z_{\text {loop }}+\frac{(2 \pi f M)^{2}}{Z_{\mathrm{A}}}
$$

where $Z_{\text {loop }}=j 2 \pi f L_{\text {loop }}$ is the input impedance of the feed loop and $Z_{\mathrm{A}}$ is the antenna impedance without the matching element. Based on (3), resistance and reactance at the input terminal of the antenna can be calculated based on (4) and (5)

$$
\begin{gathered}
R_{\text {in }}\left(f_{0}\right)=\frac{\left(2 \pi f_{0} M\right)^{2}}{R_{\mathrm{A}}\left(f_{0}\right)}, \\
X_{\text {in }}\left(f_{0}\right)=2 \pi f_{0} L_{\text {loop }} .
\end{gathered}
$$

It can be seen from (4) and (5) that the input resistance depends on the mutual inductance between the feeding loop and the patches while the reactance value is solely contributed by the loop's inductance. The mutual 
coupling, $M$ is then determined by the size of the loop and its distance from the patches. As for the loop inductance, it is mainly affected by its aspect ratio. The inductance of the triangle loop feed network, $L_{\text {loop }}$ can be approximated using (6) $[28]$

$$
L_{\text {loop }} \approx N^{2} \frac{\mu_{0} \mu_{r}}{2 \pi}\left[\begin{array}{l}
2 c \ln \left(\frac{2 c}{0.5 s}\right)+b \ln \left(\frac{2 c}{0.5 s}\right) \\
-2(b+c) \sinh ^{-1}\left(\frac{b^{2}}{\sqrt{4 b^{2} c^{2}-b^{4}}}\right) \\
-2 c \sinh ^{-1}\left(\frac{2 c^{2}-b^{2}}{\sqrt{4 b^{2} c^{2}-b^{4}}}\right)-(2 c+b)
\end{array}\right]
$$

where $b, c$, and $s$ are the dimension of the triangle loop. $N$, $\mu_{0}$, and $\mu_{r}$ are number of turns of the loop, permittivity of free space and effective permittivity of the substrate. The approximate geometrical dimension of the matching loop calculated based (5) and (6) is shown in Tab. 2.

The impedance bandwidth of the proposed antenna is enhanced by utilizing coplanar multi-resonator configuration. Three patches of different shapes were constructed to be the radiating elements. The patches resonate at three different frequencies closed to each other to form a wide impedance bandwidth to cover the entire frequency range of UHF RFID. The radiating elements of the antenna are composed of one narrow rectangular patch and two meandered patches. The physical length, $L$ of the patches can be initially approximated using the closed form expression as shown in (7)[29]

$$
L=\frac{1}{2 f_{r} \sqrt{\varepsilon_{\text {reff }}} \sqrt{\mu_{0} \varepsilon_{0}}}-2 \Delta L
$$

where $f_{\mathrm{r}}, \varepsilon_{\text {reff }}$ and $\Delta L$ are the resonant frequency, effective dielectric constant and extension of patch length due to fringing field effect. The effective dielectric constant is calculated as in (8) [30]

$$
\varepsilon_{\text {reff }}=\frac{\left(\varepsilon_{\mathrm{r}}+1\right)}{2}+\frac{\left(\varepsilon_{\mathrm{r}}-1\right)}{2}\left[1+\frac{12 h}{W}\right]^{-1 / 2}
$$

where $W$ is the width of the patch. In this design, the width of the patches is chosen to be less than the effective width to reduce the overall size of the antenna. Nevertheless, a good balance between gain performance and size is observed. Then, all three patches are fed by the triangle feed loop at each side as illustrated in Fig. 1. The antenna design was simulated using commercial electromagnetic simulator Ansoft HFSS v13 based on the approximated calculation of the antenna parameters. Afterwards, parametric refinement on the antenna parameter for the matching loop and the radiating patches geometry were carried out. The input resistance was matched by varying the distances, $d 1, d 2$ and $d 3$ of the patches from the loop. As for the reactance part, the geometry of the triangle loop, $b, c$ and $s$ were varied to get $X_{\mathrm{in}}=212 \mathrm{j} \Omega$ required to cancel the capacitive value of the microchip. FR-4 epoxy glass substrate with a dielectric constant, $\varepsilon_{\mathrm{r}}$ of 4.4 and thickness of $1.6 \mathrm{~mm}$ was used due to its cheap cost [30]. It also lowers the Q-value of the antenna thus contributes to increased bandwidth. The optimal design parameter is tabulated in Tab. 2. The antenna was then fabricated using photolithography and etching technique. The final prototype of the antenna is shown in Fig. 2. A test fixture shown in Fig. 3 was used to probe the antenna. The input impedance of the proposed antenna was then measured using the two port differential probe technique proposed by [31], [32] due the balanced feed structure of the antenna. The impedance measurement setup is shown in Fig. 4. The input impedance of the antenna was then extracted from the measured S-parameters.

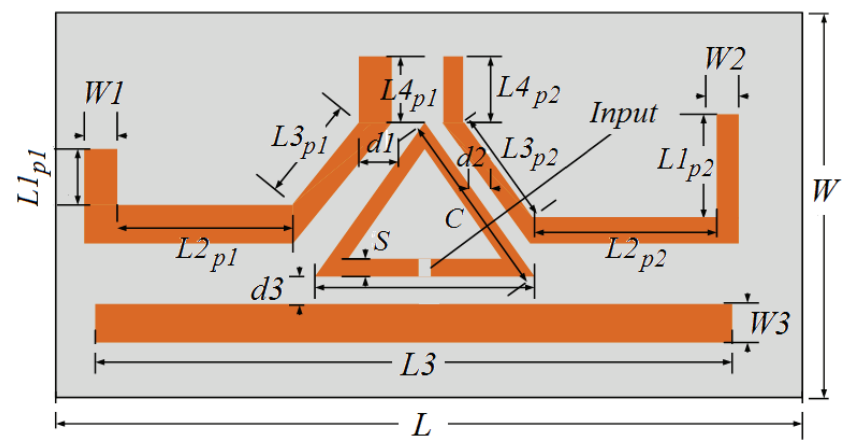

(a)

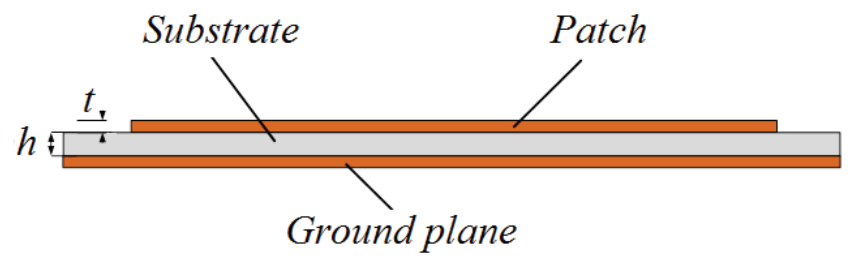

(b)

Fig. 1. Structure of the antenna. (a) Top view and (b) side view.

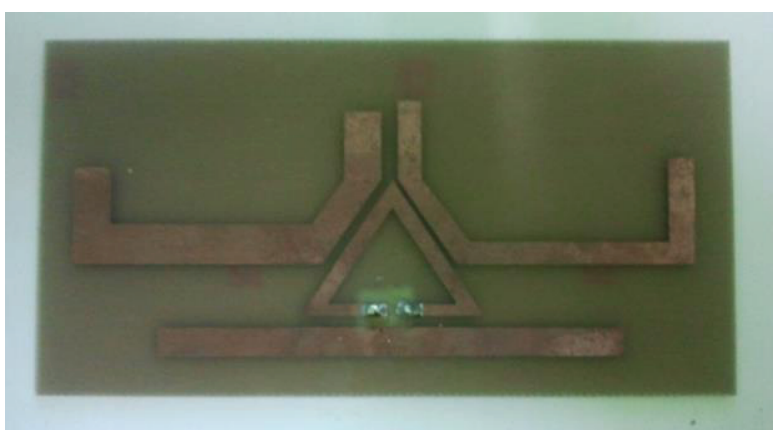

Fig. 2. Prototype of the antenna.

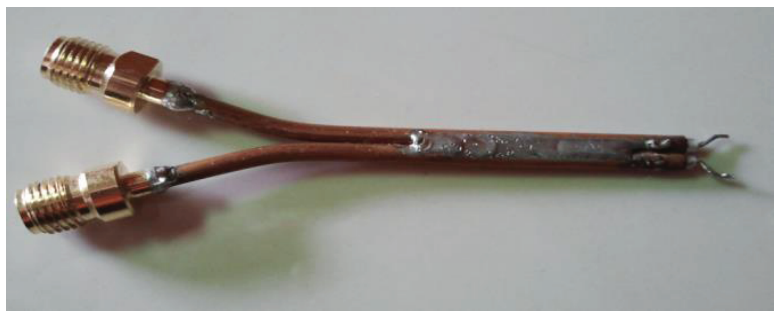

Fig. 3. Prototype of test fixture. 


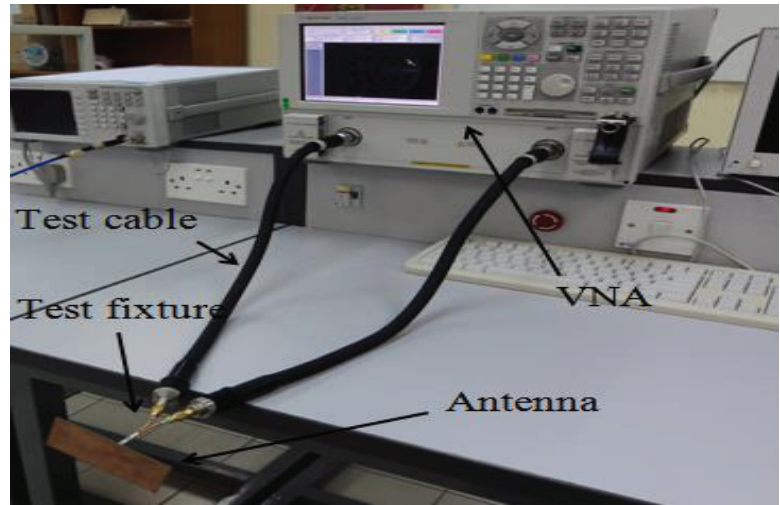

Fig. 4. Impedance measurement setup.

\begin{tabular}{|c|c|}
\hline Parameter & Value $(\mathrm{mm})$ \\
\hline$W 1$ & 7 \\
\hline$L 1_{p 1}$ & 10 \\
\hline$L 2_{p 1}$ & 37 \\
\hline$L 3_{p 1}$ & 10 \\
\hline$L 4_{p 1}$ & 12 \\
\hline$W 2$ & 5 \\
\hline$L 1_{p 2}$ & 15 \\
\hline$L 2_{p 2}$ & 37 \\
\hline$L 3_{p 2}$ & 14 \\
\hline$L 4_{p 2}$ & 14 \\
\hline$W 3$ & 5 \\
\hline$L 3$ & 86 \\
\hline$c$ & 29.4 \\
\hline$b$ & 34 \\
\hline$s$ & 2 \\
\hline$d 1$ & 2 \\
\hline$d 2$ & 1 \\
\hline$d 3$ & 2 \\
\hline$t$ & 0.0358 \\
\hline$h$ & 1.6 \\
\hline Ground plane and substrate & $130 \times 63$ \\
\hline
\end{tabular}

Tab. 2. Optimized design parameter of the proposed antenna.

\section{Results and Discussion}

The simulation and measurement results of the design are presented in this section to verify the initial deduction. The surface current density of the antenna illustrated in Fig. 5 to show the proposed antenna resonates at three different resonant frequencies $882 \mathrm{MHz}, 908 \mathrm{MHz}$ and $949 \mathrm{MHz}$. It can also be seen that the antenna exhibits linear horizontal polarization although slight cross polarization might be observed due to the meandering structure of the patches. The simulated and measured input impedance of the antenna against the conjugate impedance of the referenced microchip is shown in Fig. 6. By varying the parameter, $d_{1}, d_{2}$ and $d_{3}$ the input resistance of the antenna can be matched to the input resistance of the microchip over the UHF RFID frequency band while the size of the triangle loop feed, $b, c$ and $s$ can be adjusted to present the

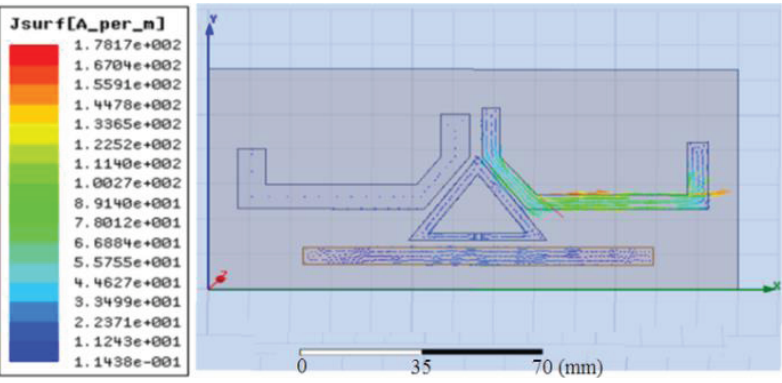

(a)

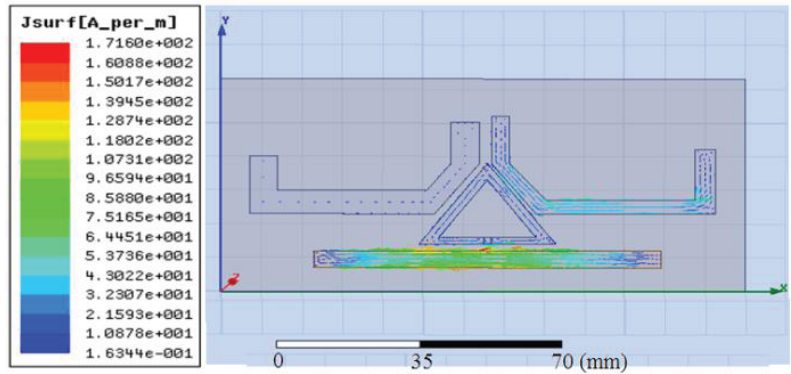

(b)

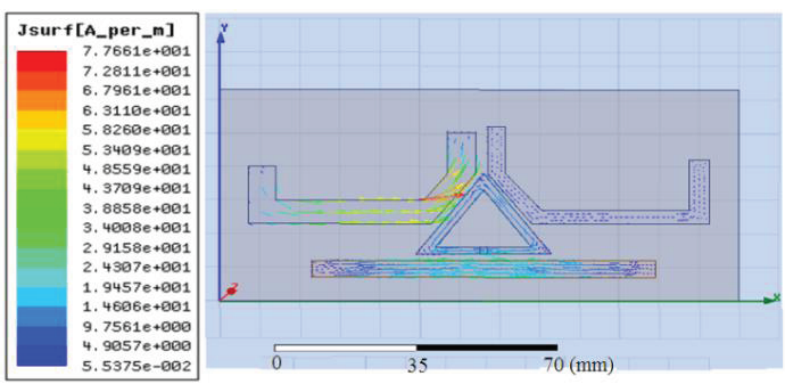

(c)

Fig. 5. Surface current distribution at three resonant frequencies. (a) $882.4 \mathrm{MHz}$, (b) $908.6 \mathrm{MHz}$ and (c) 949.3 MHz.

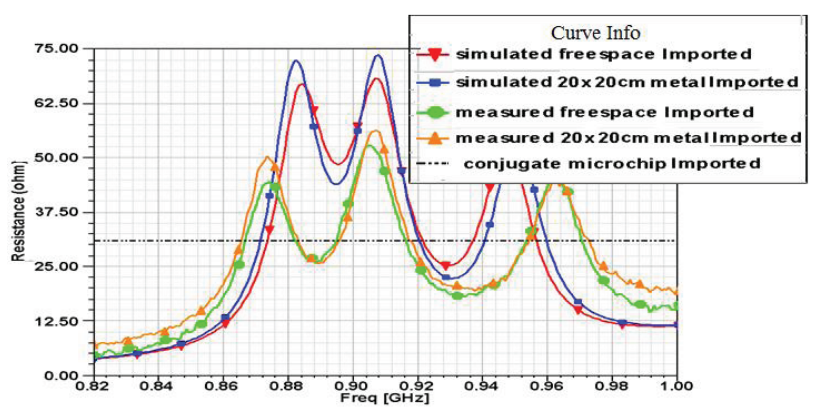

(a)

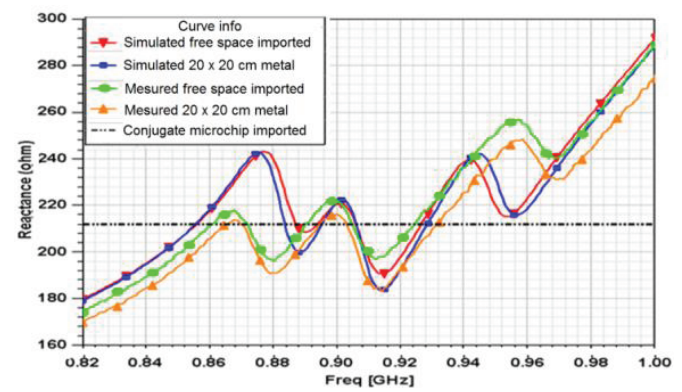

(b)

Fig. 6. Simulated and measured (a) resistance and (b) reactance value of the input impedance of the antenna against conjugate impedance of referenced microchip. 
required reactance to cancel the capacitive value of the microchip. To observe the effect of metal surface to its performance, the antenna was simulated on top of metal plane with dimension of $200 \times 200 \mathrm{~mm}^{2}$ in addition to the free space scenario. For actual measurement, the antenna was then attached to a metal plate of the same size and the impedance of the antenna was measured experimentally.

The slight difference between the simulated and measured input impedance of the proposed antenna shown in Fig. 6 was due to the fabrication inaccuracy as well as the surrounding effects when the measurement was taken.

To evaluate the impedance bandwidth of the antenna, equation (1) is used to calculate the return loss of the antenna [12], [15], [16], [22], [33]. The simulated and measured return loss for both free space and mounted on metal plane is shown in Fig. 7. Despite the difference of input impedance between the simulation and measurement, both return loss performance for both cases are $113 \mathrm{MHz}$ and $117 \mathrm{MHz}$, well over the required $100 \mathrm{MHz}$ for the entire UHF RFID operating frequency band. As for comparison of the antenna performance on free space and when it is mounted on a metal plate, a slight shift on the resonant frequency is observed on the simulation result. However, based on the measurement, the antenna input impedances on free space and when it was attached on the metal surface is almost identical. Hence, it is evident that the proposed antenna works well when being mounted on the metallic surface. In order to further investigate the performance of the antenna, the peak gain of the antenna over the UHF RFID operating frequency band was simulated and the result is shown in Fig. 8 while the simulated antenna efficiency is shown in Fig. 9. It is seen that the efficiency of the antenna is quite low around $30 \%$ thus result in low gain. This is primarily due to the thin and lossy nature of the substrate. On the other hand, the use of the low permittivity substrate would result in increase of antenna size and cost. The peak gain of the antenna is more uniform across the operating frequency of $860-960 \mathrm{MHz}$ when mounted on the metal plate as compared to free space condition. This is likely because of the reduced backside radiation due to reflection by the larger metallic surface as opposed to smaller size ground plane without the metal plate. Nevertheless, the low gain for tag antenna was not uncommon as reported in previous works since a read range of about 1 to 3 meters is enough for some of the RFID applications [17], [22], [34].

In addition, the far field radiation patterns of the antenna were measured in the anechoic chamber and compared to simulation results. The simulated and measured normalized E-field and $\mathrm{H}$-field pattern at the operating frequency of $915 \mathrm{MHz}$ are depicted in Fig. 10 respectively. It can be safely concluded the radiation pattern for both simulation and measurement results are in good agreement.

To further evaluate the performance of the antenna, the theoretical maximum read range of the antenna was calculated using Friis transmission equation (8) at three different operating frequencies as listed in Tab. 2 [3]. The

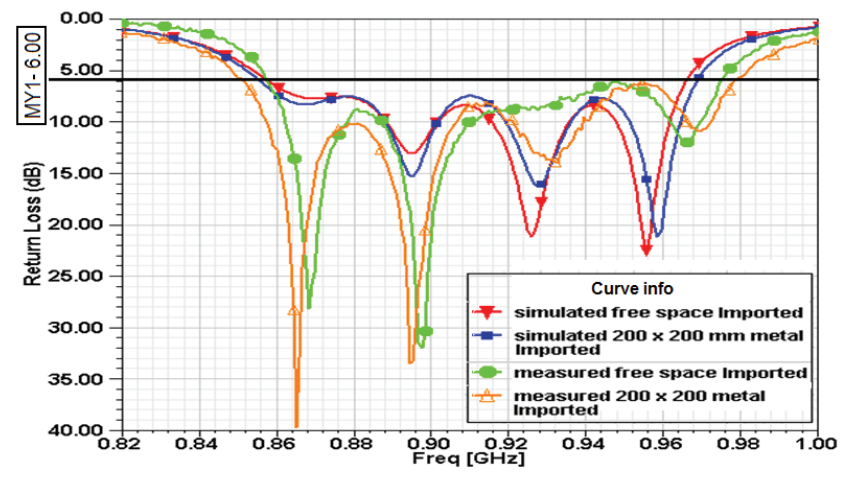

Fig. 7. Simulated and measured return loss of the antenna.

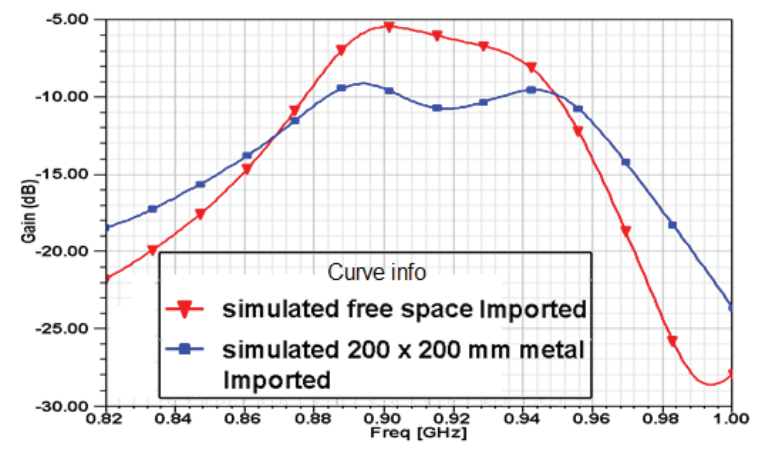

Fig. 8. Simulated peak gain of the antenna.

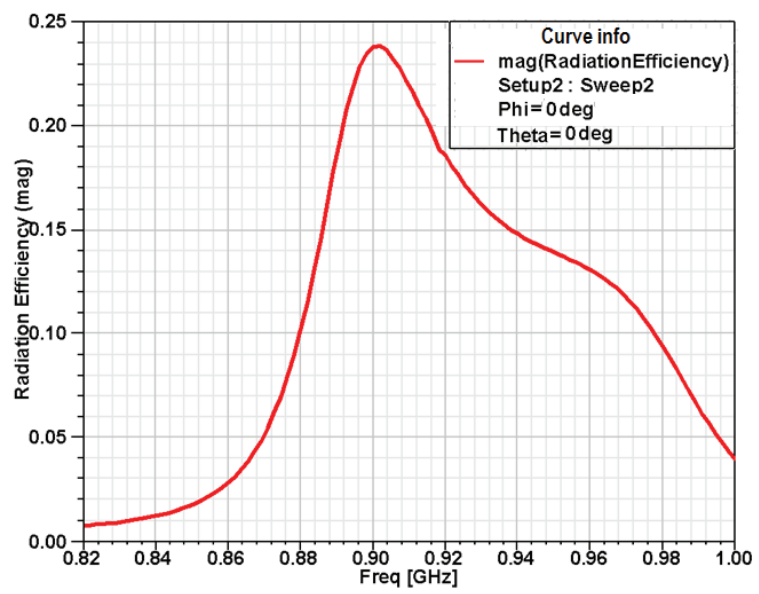

Fig. 9. Simulated antenna efficiency.

\begin{tabular}{|c|c|c|c|c|c|c|}
\hline \multirow{2}{*}{$\begin{array}{c}\text { Country/ } \\
\text { Region }\end{array}$} & $\begin{array}{c}\text { Center } \\
\text { freq., } f_{c} \\
(\mathrm{MHz})\end{array}$ & EIRP $(\mathrm{W})$ & Free space & $\begin{array}{c}200 \times 200 \mathrm{~mm}^{2} \\
\text { metal sheet }\end{array}$ & Free space & $200 \times 200 \mathrm{~mm}^{2}$ metal sheet \\
\hline Europe & 886 & 3.3 & -13.28 & -11.50 & 2.68 & 3.33 \\
\hline North America & 915 & 4 & -6.05 & -10.56 & 6.18 & 3.61 \\
\hline Japan & 954 & 4 & -11.54 & -12.06 & 2.99 & 2.80 \\
\hline
\end{tabular}

Tab. 3. Theoretical calculated read range of the antenna. 


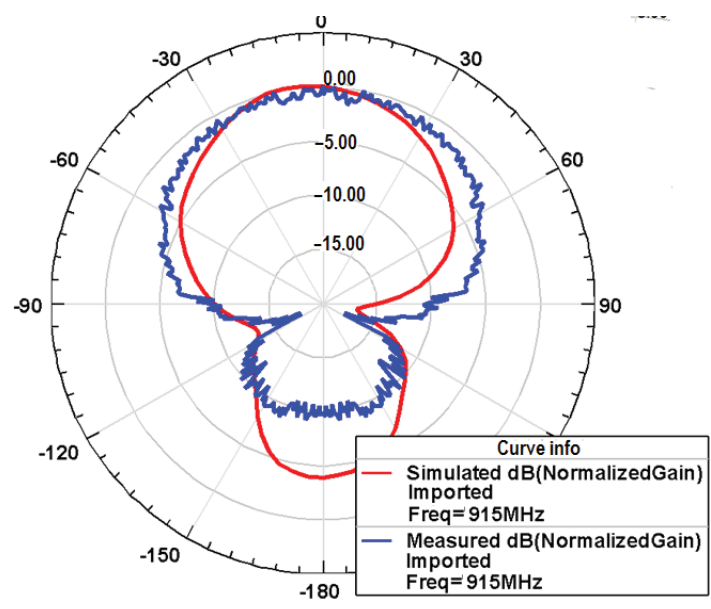

(a)

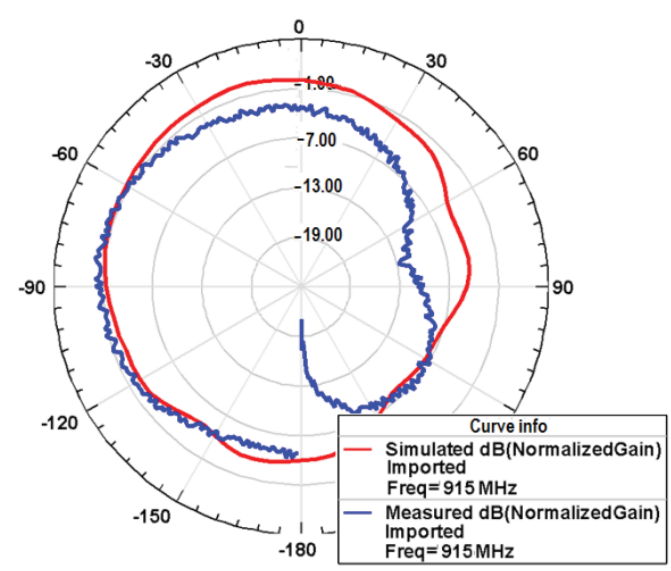

(b)

Fig. 10. Simulated and measured normalized radiation pattern at $915 \mathrm{MHz}$. (a) E-plane and (b) H-plane field pattern.

results show the antenna is able to give minimum read range of at least 2 meter worldwide as shown in Tab. 3 .

$$
r=\frac{\lambda}{4 \pi} \sqrt{\frac{P_{t} G_{t}(\theta, \phi) G_{r}(\theta, \phi) p \tau}{P_{t h}}} .
$$

$\lambda$ is the free-space wavelength of the operating frequency, $P_{t}$ represents the reader's transmitted power, $G_{t}$ is the gain of the reader's transmitting antenna, $G_{r}$ is the gain of the receiving tag antenna, $p$ accounts for the polarization mismatch between the antenna, $P_{t h}$ is the sensitivity of microchip and $\tau$ is the power transmission coefficient given by

$$
\tau=1-|\Gamma|^{2}
$$

\section{Conclusion}

A new wideband microstrip antenna for tagging metallic objects is presented in this paper. The designed tag antenna demonstrates simulated and measured impedance bandwidth of $113 \mathrm{MHz}$ and $117 \mathrm{MHz}$ based on $6 \mathrm{~dB}$ return loss. Moreover, the antenna exhibits planar configuration without any multi or cross-layered configuration which significantly reduces the fabrication cost especially for mass production. For future work, the antenna will be integrated with the referenced microchip to experimentally measure the read range of the antenna and comparison will be made with the theoretical results.

\section{Acknowledgements}

This research has been supported by the Ministry of Higher Education of Malaysia through the Fundamental Research Grant Scheme FRGS13-027-0268.

\section{References}

[1] DOBKIN, D. M. The RF in RFID : Passive UHF RFID in Practice. Massachusetts: Elsevier Inc., 2008.

[2] MARROCCO, G. The art of UHF RFID antenna design: impedance-matching and size-reduction techniques. IEEE Antennas and Propagation Magazine, 2008, vol. 50, no. 1, p. 66 to 79. DOI: 10.1109/MAP.2008.4494504

[3] RAO, K. V. S., et al. Antenna design for UHF RFID tags: A review and a practical application. IEEE Transactions on Antennas and Propagation, 2005, vol. 53, no. 12, p. 3870-3876. DOI: 10.1109/TAP.2005.859919

[4] YANG, B., FENG, Q. A folded dipole antenna for RFID tag. In Proceedings of International Conference on Microwave and Millimeter Wave Technology. Nanjing (China), 2008, p. 1047-1049. DOI: 10.1109/ICMMT.2008.4540601

[5] CHOI, Y., et al. Design of modified folded dipole antenna for UHF RFID tag. Electronics Letters, 2009, vol. 45, p. 387-389. DOI: $10.1049 / \mathrm{el} .2009 .0198$

[6] MONTI, G., et al. Broad-band dipole for RFID applications. Progress In Electromagnetics Research C, 2010, vol. 12, p. 163 to 172. doi:10.2528/PIERC10012606

[7] PROTHRO, J. T., et al. The effects of a metal ground plane on RFID tag antennas. In Proceedings of the IEEE Antennas and Propagation Society International Symposium, 2006. DOI: 10.1109/APS.2006.1711302

[8] GHANNAY, N., et al. Effects of metal plate to RFID tag antenna parameters. In Proceedings of the Mediterrannean Microwave Symposium 2009. Tangiers (Morrocco), 2009, p. 1-3. DOI: 10.1109/MMS.2009.5409801

[9] TASHI, T., et al. A complete planner design of microstrip patch antenna for a passive UHF RFID tag. In Proceedings of the 17th International Conference on Automation and ComputingICAC 2011. Huddersfield (UK), 2011, p. 12-17.

[10] SON, H.-W., et al. Design of wideband RFID tag antenna for metallic surfaces. Electronics Letters, 2006, vol. 42, no. 5, p. 263 to 265.DOI: $10.1049 / \mathrm{el}: 20064323$

[11] CHOI, W., et al. An RFID tag using a planar inverted-F antenna capable of being stuck to metallic objects. ETRI Journal, 2006, vol. 20, p. 216-218. DOI: DOI: 10.4218/etrij.06.0205.0082

[12] SON, H.-W., JEONG, S.-H. Wideband RFID tag antenna for metallic surfaces using proximity-coupled feed. IEEE Antennas and Wireless Propagation Letters, 2011, vol. 10, p. 377-380. DOI: 10.1109/LAWP.2011.2148151

[13] MO, L., QIN, C. Tunable compact UHFRFID metal tag based on CPW open stub feed PIFA antenna. International Journal of Antennas and Propagation, 2012, 8 p. DOI: $10.1155 / 2012 / 167658$ 
[14] Regulation, U. Regulatory status for using RFID in the UHF spectrum, Cited 28-09-2012. Available: http://www.gs1.org/docs /epcglobal/UHF_Regulations.pdf

[15] MO, L., et al. Broadband UHF RFID tag antenna with a pair of U slots mountable on metallic objects. Electronics Letters, 2008, vol. 44, p. 1173-1174. DOI: 10.1049/el:20089813

[16] HUANG, J. Z., et al. A compact broadband patch antenna for UHF RFID tags. In Proceedings of the Asia Pacific Microwave Conference APMC2009. Singapore, 2009, p. 1044-1047. DOI: 10.1109/APMC.2009.5384364

[17] LAI, M., et al. Low-profile broadband RFID tag antennas mountable on metallic objects. In Proceedings of the IEEE Antennas and Propagation Society International Symposium. Toronto (Canada), 2010, 4 p. DOI: 10.1109/APS.2010.5561167

[18] TAN, L. R., WU, R. X. Miniaturized broadband tag antenna for multi-standard UHF RFID applications. In Proceedings of the IEEE International Conference on Microwave Technology and Computational Electromagnetics. Beijing (China), 2011, p. 274 to 276. DOI: 10.1109/ICMTCE.2011.5915510

[19] LU, J.-H., ZHENG, G.-T. Planar broadband tag antenna mounted on the metallic material for UHF RFID system. IEEE Antennas and Propagation Magazine, 2011, vol. 10, p. 1405-1408. DOI: 10.1109/LAWP.2011.217899

[20] EUNNI, M. S. M., DEAVOURS, D. D. A novel planar microstrip antenna design for UHF RFID. Journal of Systemics, Cybernetics and Informatics, 2007, vol. 5, no. 1, p. 6-10.

[21] TASHI, et al. Design and simulation of UHF RFID tag antennas and performance evaluation in presence of a metallic surface. In Proceedings of the 5th International Conference on Software, Knowledge Information, Industrial Management and Applications. Benevento (Italy), 2011, 5 p. DOI: 10.1109/SKIMA.2011.6089974

[22] CHO, H.-G., et al. Design of an embedded-feed type microstrip patch antenna for UHF radio frequency identification tag on metallic objects. IET Microwaves, Antennas \& Propagation, 2010, vol. 4, p. 1232-1239. DOI:10.1049/iet-map.2009.040

[23] MO, L., QIN, C. Planar UHF RFID tag antenna with open stub feed for metallic objects. IEEE Transactions on Antennas and Propagation, 2010, vol. 58, no. 9, p. 3037-3043. DOI: 10.1109/TAP.2010.2052570

[24] Alien. Alien Higgs 3 EPC Class 1 Gen 2 RFID Tag IC. Cited 20-10-2012. Available: http://www.alientechnology.com/docs/ products/Alien-Technology-Higgs-3-ALC-360.pdf

[25] LOO, C.-H., et al. Chip impedance matching for UHF RFID tag antenna design. Progress In Electromagnetics Research, 2008, vol. 81, p. 359-370. DOI:10.2528/PIER08011804

[26] BIRD, T. S. Definition and misuse of return loss. IEEE Antennas and Propagation Magazine, 2009, vol. 51, p. 166-167.

[27] SON, H.-W., PYO, C.-S. Design of RFID tag antennas using an inductively coupled feed. Electronics Letters, 2005, vol. 41, no. 18, p. 994-996. DOI: 10.1049/el:20051536

[28] GROVER, F. W. Inductance Calculations: Working Formulas and Tables. New York: D. Van Nostrand, 1946.

[29] Balanis, C. A. Antenna Theory Analysis and Design. 3rd ed. New Jersey: John Wiley \& Sons, 2005.

[30] KUMAR, G., RAY, K. P. Broadband Microstrip Antenna. Noorwood, MA: Artech House, 2003.

[31] KUO, S.-K., et al. An accurate method for impedance measurement of RFID tag antenna. Progress In Electromagnetics Research, 2008, vol. 83, p. 93-106. DOI:10.2528/PIER08042104

[32] QING, X. et al. Impedance characterization of RFID tag antennas and application in tag co-design. IEEE Transactions on Microwave Theory and Techniques, 2009, vol. 57, p. 1268-1274. DOI: 10.1109/TMTT.2009.2017288
[33] XU, L., et al. UHF RFID tag antenna with broadband characteristic. Electronics Letters, 2008, vol. 44, no. 2, p. 79-80. DOI: $10.1049 / \mathrm{el}: 20083009$

[34] LU, J.-H., HUNG, K.-T. Planar inverted-E antenna for UHF RFID tag onmetallic objects with bandwidth enhancement. Electronics Letters, 2010, vol. 46, no. 17, p. 1182-1183. DOI: 10.1049/el.2010.0817

\section{About the Authors ...}

Mohd Saiful Riza BASHRI was born in Selangor, Malaysia, in May 1985. He received the B.Sc. degrees in Communication Engineering from International Islamic University Malaysia (IIUM) in 2009. He worked for Telekom Malaysia (TM) from 2009 to 2011 as an assistant manager which oversaw the planning of submarine cable network in the South East Asia region. Currently he is pursuing his master degree at IIUM. His research interests include antenna design, RFID and microwave devices.

Muhammad Ibn IBRAHIMY was born in Sirajgonj, Bangladesh, in August 1962. He received the B.Sc. and M.Sc. degrees in Applied Physics and Electronics from the University of Rajshahi, Bangladesh, in 1985 and 1986, respectively, and the Ph.D. degree in Biomedical Signal Processing from the National University of Malaysia, in 2001. From 2001 to 2003, he was a Postdoctoral Fellow in the Dept. of Electrical and Electronic Engineering at the Mie University of Japan. He is now Associate Professor in the Dept. of Electrical and Computer Engineering, IIUM. Dr. Ibrahimy is a senior member of the Inst. of Electrical and Electronics Engineers (IEEE), a member of the Bangladesh Computer Society (BCS) and the Bangladesh Electronics Society (BEC). His research interests are Analog and Digital Electronic System Design, Medical and Industrial Instrumentation, Biomedical Signal Processing, VLSI Design, RFID and Computer Networks in Telemedicine. He has published about 50 research articles in peer reviewed journals, conferences and 2 books.

S. M. A. MOTAKABBER was born in Naogaon, Bangladesh, in May 1966. He received the B.Sc. and M.Sc. degrees in Applied Physics and Electronics from the University of Rajshahi, Bangladesh, in 1986 and 1987, respectively, and the Ph.D. degree in Electrical, Electronic and Systems Engineering from the National University of Malaysia, in 2011. From 1993 to 2011, he was an Associate Professor in the Dept. of Applied Physics and Electronic Engineering, University of Rajshahi, Bangladesh. He is now an Assistant Professor in the Dept. of Electrical and Computer Engineering, IIUM. Dr. Motakabber is a member of the Inst. of Electrical and Electronics Engineers (IEEE), a life member of the Bangladesh Association for Advancement of Science (BAAS) and the Bangladesh Electronics Society (BEC). His research interests are Analog and Digital Electronic System Design, Medical and Industrial Instrumentation, VLSI Design, RFID, Robotics, Automation and Computer Control Systems. He has published about 20 research articles in peer reviewed journals, conferences and 1 book. 